\title{
DESENVOLVIMENTO DE CATALISADOR ÓXIDO DE NIÓBIO SULFATADO PARA A SÍNTESE DE ÉSTERES ETÍLICOS A PARTIR ÓLEO DE ELEVADA ACIDEZ
}

\author{
M. D. POLICANO ${ }^{1}$, L. S. MARTIN ${ }^{1}$, L. M. CARNEIRO ${ }^{1}$, J. D. RIVALDI ${ }^{1}$, \\ H. F. DE CASTRO ${ }^{1}$ \\ ${ }^{1}$ Escola de Engenharia de Lorena - USP, Departamento de Engenharia Química \\ E-mail para contato: danielrivaldi@usp.br
}

\begin{abstract}
RESUMO - A catálise ácida heterogênea representa uma alternativa à tradicional via alcalina para a produção de ésteres alquílicos a partir de óleos de alto conteúdo em ácidos graxos livres. Neste trabalho foi desenvolvido o catalisador óxido de nióbio sulfatado obtido por impregnação de óxido de nióbio com ácido sulfúrico $(0,5 \mathrm{M})$ a $90^{\circ} \mathrm{C}$ sobre refluxo e agitação constante $(500 \mathrm{rpm})$ por $3 \mathrm{~h}$. O catalisador resultante foi submetido a tratamento térmico a $500^{\circ} \mathrm{C}$ por $5 \mathrm{~h}$ e caracterizado quanto à cristalinidade (XRD), morfologia (MEV) e acidez titulável (mmol H+/g). A reação de transesterificação foi conduzida com óleo de andiroba (índice de acidez: $33,1 \mathrm{mg} \mathrm{KOH} / \mathrm{g}$ ) e etanol anidro em condições variáveis de temperatura $\left(160-260^{\circ} \mathrm{C}\right)$, relação molar óleo/etanol $(1: 50-1: 120)$ e concentração de catalisador óxido de nióbio sulfatado de $5 \%(\mathrm{~m} / \mathrm{m})$. A conversão máxima do óleo de andiroba em ésteres etílicos foi de $67 \%$ à temperatura de $260^{\circ} \mathrm{C}$ e relação molar 1:120 óleo/etanol.
\end{abstract}

\section{INTRODUÇÃO}

Os problemas ambientais derivados do acúmulo de poluentes gerados pela combustão de petróleo, bem como o alto preço de mercado desta commodity, estimulam a utilização de biocombustíveis alternativos. Os biocombustíveis, como o biodiesel (éster etílico ou metílico de ácidos graxos), representam uma importante parcela da matriz energética de países emergentes, contribuindo com o aumento de renda e geração de emprego. A obrigatoriedade da adição de biodiesel ao diesel comum estipulada pela Lei Federal $n^{\circ}$ 11097/2005, tem estimulado o crescimento da indústria e o número de pesquisas relacionadas com a produção de biodiesel no Brasil (Vaccaro et al., 2010).

$\mathrm{Na}$ indústria, o biodiesel é produzido pela transesterificação de óleo vegetal e metanol na presença de catalisador homogêneo de caráter básico $(\mathrm{KOH}$ ou $\mathrm{NaOH})$. Devido à abundância de etanol no mercado nacional, o biodiesel brasileiro é produzido principalmente por transesterificação de óleo vegetal com etanol, incluindo óleo de soja, algodão e pinhão manso (Suarez; Meneghetti, 2007). Por outro lado, o uso de catalisadores homogêneos básicos apresenta desvantagens como formação de sabão, requerimento de elevado número de etapas de separação e purificação de biodiesel e a impossibilidade de reutilização em processos de transesterificação consecutivos.

Óleos vegetais não comestíveis (andiroba, macaúba e palma) e óleos de origem microbiana, representam matérias-primas alternativas para a produção de biodiesel. 
Entretanto, o alto valor de acidez destes óleos constitui um obstáculo para a utilização de catalisadores normalmente utilizados na indústria. Neste sentido, os catalisadores heterogêneos ácidos constituem uma alternativa promissora para contornar o problema da saponificação originado pela utilização de catalisadores básicos com óleos de alto índice de acidez (Kiss et al., 2006).

Devido aos grandes investimentos no setor de produção de biodiesel e à necessidade da busca de novas matérias-primas e insumos para a indústria de biodiesel, o desenvolvimento de novos catalisadores constitui uma fronteira para novas pesquisas. Desta forma, o presente trabalho teve como objetivo testar a eficiência de catalisadores heterogêneos ácidos, particularmente, óxido de nióbio sulfatado, na produção de ésteres etílicos a partir de óleos vegetais de elevada acidez.

\section{MATERIAIS E MÉTODOS}

\subsection{Materiais}

Ácido nióbico (óxido de nióbio hidratado) amorfo com elevada área superficial (BET $180 \mathrm{~m}^{2} / \mathrm{g}$ ) e elevada força ácida (equivalente a uma solução 70\% de ácido sulfúrico) com teor da ordem de $80 \%$ em $\mathrm{Nb}_{2} \mathrm{O}_{5}$ foi gentilmente cedido pela Companhia Brasileira de Metalurgia e Mineração (Minas Gerais) e utilizado como base para a preparação do catalisador. Óleo de andiroba foi gentilmente doado pela Pulcra (Jacareí - SP) e utilizado como matéria-prima para reações de alcoólise com etanol anidro (98\%, Vetec). O óleo de andiroba apresenta uma composição aproximada em ácido graxos de 46,2-54,6\% Oleico, 26,8-28,3\% Palmítico, 7,69,1\% Linoleico $\left(\mathrm{C}_{18: 2}\right), 7,7-8,7 \%$, Esteárico, 1,5-0\% Linoleico $\left(\mathrm{C}_{18: 3}\right), 0,1-0,5 \%$ Mirístico, 8,4-2,6\% outros ácidos graxos.

\subsection{Preparação do catalisador óxido de nióbio sulfatado}

$\mathrm{O}$ óxido de nióbio sulfatado $\left(\mathrm{Nb}_{2} \mathrm{O}_{5} / \mathrm{H}_{2} \mathrm{SO}_{4}\right)$ foi preparado a partir de uma mistura de 5 g de óxido de nióbio, $5 \mathrm{~mL}$ de $\mathrm{H}_{2} \mathrm{SO}_{4}(0,5 \mathrm{M})$ e $15 \mathrm{~mL}$ de água deionizada em reator de vidro a $90^{\circ} \mathrm{C}$ sob refluxo e agitação constante $(500 \mathrm{rpm})$ por $3 \mathrm{~h}$. O material filtrado foi seco a $100^{\circ} \mathrm{C}$ por $12 \mathrm{~h}$. Em seguida, a amostra foi submetida a tratamento térmico a $500^{\circ} \mathrm{C}$ por $5 \mathrm{~h}$.

\subsection{Catálise heterogênea ácida}

O catalisador sintetizado foi avaliado quanto ao poder catalítico em reações de transesterificação. Os catalisadores foram secos a $120^{\circ} \mathrm{C}$ por $2 \mathrm{~h}$ antes de sua utilização. As reações foram conduzidas em reator cilíndrico de aço inoxidável de $150 \mathrm{~mL}$ de volume útil em condições variáveis de temperatura $\left(160-260^{\circ} \mathrm{C}\right)$, razão molar de etanol para óleo $(55$ 120) e concentração de catalisador $(2-5 \% \mathrm{~m} / \mathrm{m})$. A pressão interna do reator correspondeu à pressão de vapor do componente mais volátil da mistura reacional. $\mathrm{O}$ sistema reacional foi mantido sobre aquecimento e agitação magnética constante por um período máximo de $8 \mathrm{~h}$.

\subsection{Purificação de ésteres etílicos}

Ao término de cada reação, o meio reacional foi resfriado e centrifugado a $1570 \times g$ por 15 minutos para sedimentação do catalisador. O sobrenadante foi transferido para um funil de 
decantação e lavado com igual volume de água por 3 vezes por $12 \mathrm{~h}$. A fase superior, composta pelos ésteres etílicos, foi submetida à evaporação em rota-evaporador para separação do etanol remanescente e água, posteriormente os ésteres foram secos com sulfato de sódio anidro. O catalisador sedimentado foi resuspenso com terc-butanol, centrifugado e seco a $100{ }^{\circ} \mathrm{C}$ por $24 \mathrm{~h}$ para armazenamento.

\subsection{Metodologia analítica}

Os valores de índice de acidez, umidade, densidade e viscosidade absoluta do óleo e ésteres produzidos foram determinados conforme metodologia descrita por Carvalho (2011).

A estrutura cristalina do catalisador foi determinada por difração de Raio-X (XRD) com um PanAnalytical diffractometer (Xpert PRO model) com Cu K $(\approx 1.5418 \AA$ ) como o incidente de radiação, operando em $40 \mathrm{kV}$ e $30 \mathrm{~mA}$. O espectro de XRD foi analisado baseado na informação dada pelo cartão ICSD. As microimagens da estrutura do catalisador sintetizado foram adquiridas por microscopia eletrônica de varredura por meio microscópio LEO 1450 VP - LEISS, operando em uma voltagem de aceleração de $20 \mathrm{kV}$.

A acidez do catalisador foi obtida por titulação e expressa em mmol $\mathrm{H}+/ \mathrm{g}$ catalisador. Para tanto, $100 \mathrm{mg}$ de catalisador foram deixados em contato com $20 \mathrm{~mL}$ de $\mathrm{NaOH} 0,1 \mathrm{M}$ por $3 \mathrm{~h}$ sob leve agitação. Após este período, foram obtidas alíquotas da solução básica e titulada com $\mathrm{HCl}$ 0,1 M para determinação da quantidade de $\mathrm{NaOH}$ que reagiu com o material.

O rendimento de conversão de óleo de andiroba em ésteres etílicos foi determinada por Ressonância Magnética Nuclear $\left(\mathrm{RMN}^{1} \mathrm{H}\right)$ em espectrômetro Varian Mercury $300 \mathrm{MHz}$, utilizando clorofórmio deuterado $\left(\mathrm{CDCl}_{3}\right)$ como solvente e $0,3 \%$ de tetrametilsilano (TMS) como padrão interno. Os cálculos de conversão em ésteres foram realizados conforme metodologia validada por Paiva et al (2013). A metodologia de cálculo que determina as conversões dos ésteres etílicos durante uma reação de transesterificação consiste na identificação das moléculas presentes na região de 4,05 a 4,35 ppm do espectro de $\mathrm{RMN}^{1} \mathrm{H}$.

\section{RESULTADOS E DISCUSSÃO}

\subsection{Caracterização do nióbio sulfatado}

$\mathrm{O}$ catalisador óxido de nióbio sulfatado $\left(\mathrm{Nb}_{2} \mathrm{O}_{5} / \mathrm{H}_{2} \mathrm{SO}_{4}\right)$ foi avaliado quanto à cristalinidade, morfologia e acidez. A Figura 1 mostra o difratograma de raio-X do óxido de nióbio sem tratamento térmico, óxido de nióbio e óxido de nióbio sulfatado submetidos a tratamento térmico. A análise de difratograma da Figura 1a mostra que o óxido de nióbio não calcinado apresenta espectro característico de estruturas amorfas sem picos definidos, geralmente associados à presença de água estrutural e impurezas (Nowak; Ziolek, 1999). O catalisador óxido de nióbio sulfatado (Figura 1c), obtido por impregnação de ácido sulfúrico e calcinação a $500^{\circ} \mathrm{C}$, apresenta picos pronunciados característicos de fases cristalinas na região de 23, 28, 36, 51 e 56 (2Ө) (Melo et al., 2012). Estes picos são similares aos observados no espectro de óxido de nióbio submetido a tratamento térmico (Figura 1b). O óxido de nióbio apresenta estrutura policristalina (polimorfismo), conforme o tratamento térmico ao qual foi submetido em contato com ar ou oxigênio. 


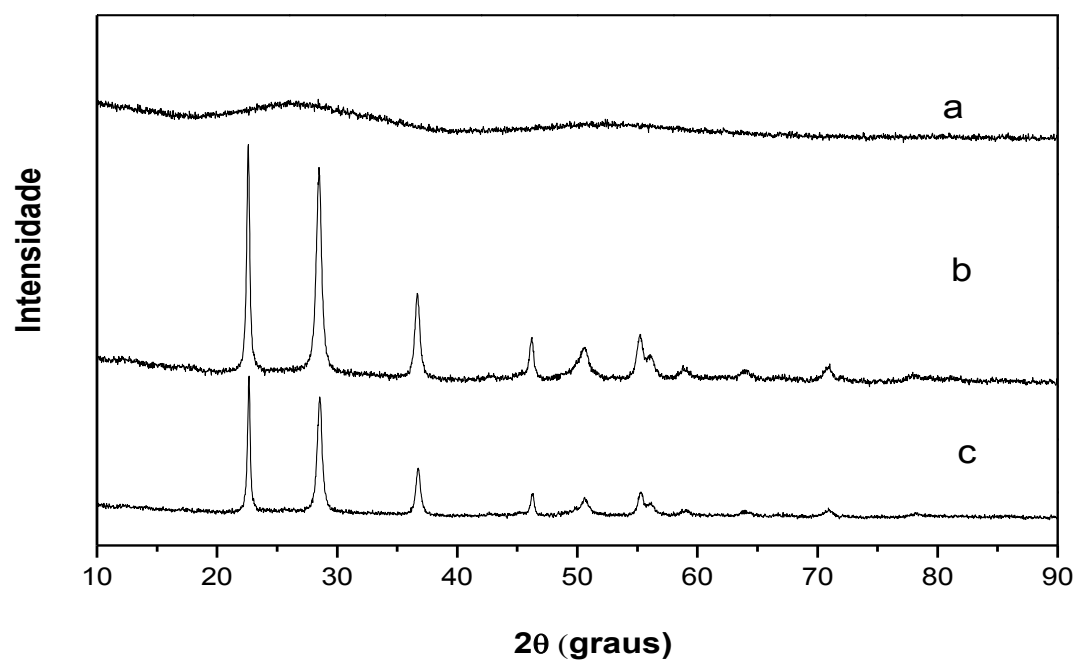

Figura 1 - Difratograma de Raio-X (XRD) de $\mathrm{Nb}_{2} \mathrm{O}_{5}$-não calcinado (a), $\mathrm{Nb}_{2} \mathrm{O}_{5}$ tratado a $500{ }^{\circ} \mathrm{C}$ (b) e catalisador $\mathrm{Nb}_{2} \mathrm{O}_{5} / \mathrm{H}_{2} \mathrm{SO}_{4}$ obtido por impregnação com ácido sulfúrico e tratamento a $500{ }^{\circ} \mathrm{C}(\mathrm{c})$.

A cristalização do óxido de nióbio se inicia a $500^{\circ} \mathrm{C}$, originando principalmente estruturas de sistemas monoclínico, hexagonal e ortorrômbico (Nowak; Ziolek, 1999). A partir de material amorfo, o óxido de nióbio cristaliza a temperatura baixa $\left(400-500{ }^{\circ} \mathrm{C}\right)$, média $\left(800{ }^{\circ} \mathrm{C}\right)$ ou alta $\left(1000{ }^{\circ} \mathrm{C}\right)$, sendo esta última condição promotora de planos mais ordenados e cristais resistentes. $\mathrm{O}$ aumento da temperatura de calcinação reduz a área superficial do catalisador devido à formação de cristais, que por sua vez diminui o número de sítios ativos ácidos do catalisador (Nowak; Ziolek, 1999). O perfil cristalino do óxido de nióbio é influenciado, não apenas pela temperatura de calcinação, mas também pelo tipo de minério utilizado, impurezas presentes, e qualquer interação com outros componentes durante o desenvolvimento do catalisador. Estas interações podem influenciar as propriedades físicas (área superficial) e químicas (acidez) dos sistemas catalíticos contendo pentóxido de nióbio. Na Figura 1c observa-se que o processo de impregnação com ácido sulfúrico não afetou o espectro, e consequentemente a estrutura cristalina do suporte (óxido de nióbio) após a calcinação.

A formação de cristais de óxido de nióbio foi confirmada mediante imagens obtidas por microscopia eletrônica de varredura - MEV (Figura 2).
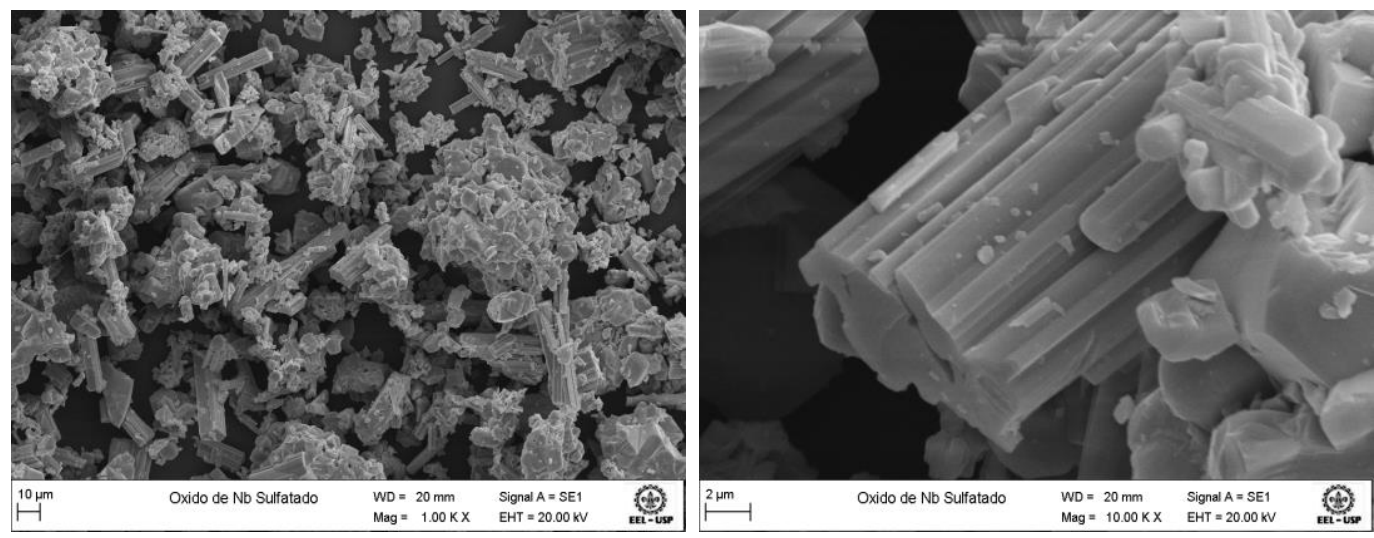

Figura 2 - Microfotografias (MEV) de catalisador óxido de nióbio sulfatado $\left(\mathrm{Nb}_{2} \mathrm{O}_{5} / \mathrm{H}_{2} \mathrm{SO}_{4}\right)$. 
O valor de acidez titutável e umidade do catalisador óxido de nióbio sulfatado são apresentados na Tabela 1 . O valor de acidez de $1,63 \mathrm{mmol} \mathrm{H}^{+} / \mathrm{g}$ indica impregnação efetiva do grupo sulfato na estrutura cristalina do óxido de nióbio. A acidez do catalisador é fundamental para a utilização efetiva em processos de conversão de óleos ácidos em ésteres.

Tabela 1- Propriedades físico-químicas do catalisador $\mathrm{Nb}_{2} \mathrm{O}_{5} / \mathrm{H}_{2} \mathrm{SO}_{4}$

\begin{tabular}{lc}
\hline \multicolumn{1}{c}{ Propriedade } & Valores \\
\hline Acidez $(\mathrm{mmol} \mathrm{H}+\mathrm{g})$ & 1,63 \\
Umidade $(\%)$ & 4,31 \\
\hline
\end{tabular}

\subsection{Propriedades do óleo de andiroba}

As características do óleo de andiroba apresentadas na Tabela 2 indica tratar-se de óleo com elevado índice de acidez $(33,11 \mathrm{mg} \mathrm{KOH} / \mathrm{g})$. O índice de acidez está relacionado diretamente com a concentração de ácidos graxos livres e denota o grau de degradação parcial dos triglicerídeos presentes no óleo vegetal. Óleos com valores de acidez superiores a 5,0 mg $\mathrm{KOH} / \mathrm{g}$, quando transesterificados na presença de catalisadores homogêneos básicos, promovem a saponificação, desativação do catalisador e formação de água (Knothe et al., 2006). Observa-se ainda que os valores de umidade, viscosidade dinâmica e densidade foram similares aos observados na literatura científica (Carvalho, 2011).

Tabela 2- Propriedades físico-químicas do óleo de Andiroba.

\begin{tabular}{lc}
\cline { 2 - 2 } \multicolumn{1}{c}{ Propriedades } & Óleo de andiroba \\
\hline Massa molar $(\mathrm{g} / \mathrm{mol})$ & 830 \\
Viscosidade $(\mathrm{cP})$ & 35,7 \\
Densidade $\left(\mathrm{g} / \mathrm{cm}^{3}\right)$ & 0,931 \\
Umidade $(\%)$ & $<1 \%$ \\
Acidez $(\mathrm{mg} \mathrm{KOH} / \mathrm{g})$ & 33,11 \\
\hline
\end{tabular}

\subsection{Produção de ésteres etílicos}

A eficiência do catalisador $\left(\mathrm{Nb}_{2} \mathrm{O}_{5}\right.$ - Sulfato) foi avaliada em reações de síntese de ésteres de etila a partir do óleo de andiroba sob diferentes condições (temperatura, razão molar etanol:óleo e proporção de catalisador). Os resultados obtidos da conversão do óleo em ésteres etílicos e viscosidade são apresentados na Tabela 3.

O máximo rendimento em ésteres $(67 \%, \mathrm{~m} / \mathrm{m})$ foi alcançado sob as condições de experimentação do ensaio 7. O aumento da temperatura de reação para a mesma relação molar de etanol: óleo promoveu a obtenção de maiores concentrações de ésteres etílicos (Reações 3 a 5). Verifica-se ainda o aumento da conversão com o incremento da temperatura de reação para a mesma relação molar de etanol:óleo.

A elevada concentração de etanol na mistura reacional exerceu efeito positivo na conversão de óleo de andiroba, promovendo rendimentos até $15 \%$ superior para reações realizadas na mesma temperatura (Reações 5 e 7). A maior quantidade de álcool no meio reacional desloca o equilíbrio da reação, favorecendo a formação de ésteres, sendo o efeito favorável desta variável observado em diversos estudos (Brandão et al., 2009; Pietre et al., 2010). 
Tabela 3 - Resultados de transesterificação de óleo de andiroba de alta acidez na presença de catalisador heterogêneo ácido

\begin{tabular}{ccccccc}
\hline Reação & $\begin{array}{c}\text { EtOH: Óleo } \\
(\mathrm{mol} / \mathrm{mol})\end{array}$ & $\begin{array}{c}\text { Catalisador }^{\mathrm{a}} \\
(\%, \mathrm{~m} / \mathrm{m})\end{array}$ & $\begin{array}{c}\text { Temperatura } \\
\left({ }^{\circ} \mathrm{C}\right)\end{array}$ & $\begin{array}{c}\mu_{\mathrm{f}} \\
(\mathrm{cP})\end{array}$ & $\begin{array}{c}\text { Tempo } \\
(\mathrm{h})\end{array}$ & $\begin{array}{c}\text { Rendimento }^{\mathrm{b}} \\
(\%, \mathrm{~m} / \mathrm{m})\end{array}$ \\
\hline 1 & 55 & 5 & 160 & 22,4 & 8 & 40,1 \\
2 & 95 & 5 & 180 & 20,0 & 8 & 47,5 \\
3 & 95 & 5 & 200 & 20,8 & 8 & 52,1 \\
4 & 95 & 5 & 230 & 22,2 & 8 & 54,3 \\
5 & 95 & 5 & 260 & 20,4 & 8 & 58,3 \\
6 & 120 & 5 & 230 & 17,1 & 8 & 60,4 \\
7 & 120 & 5 & 260 & 17,2 & 4 & 67,0 \\
\hline
\end{tabular}

${ }^{\mathrm{a}}$ Catalisador óxido de nióbio sulfatado $\left(\mathrm{Nb}_{2} \mathrm{O}_{5} / \mathrm{H}_{2} \mathrm{SO} 4\right)$; ${ }^{\mathrm{b}}$ rendimento calculado por $\mathrm{RMN}^{1} \mathrm{H}$; $\mu_{\mathrm{f}}$ : viscosidade cinemática final.

A Figura 3 ilustra o espectro de $\mathrm{RMN}^{1} \mathrm{H}$ obtido na reação 7 . A formação dos ésteres de etila foi confirmada pelo sinal em 4,08 ppm, sendo a área $1 / 8$ da área total dos hidrogênios do carbono-etoxílico $\left(-\mathrm{OCH}_{2} \mathrm{CH}_{3}\right)$ e cujo sinal aparece na região compreendida entre 4,05 e 4,2 ppm. Verifica-se ainda o desaparecimento parcial do sinal de glicerol em 4,16 ppm, correspondente aos átomos de hidrogênio do grupo $\mathrm{CH}_{2}$ do glicerol, indicando a conversão incompleta de triglicerídeos em ésteres da ordem de 67,0\%.

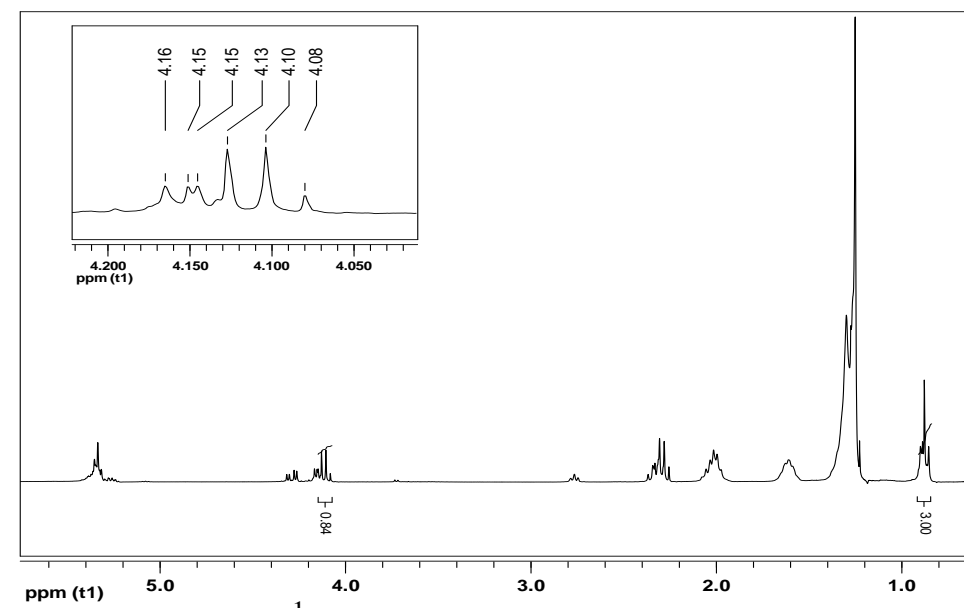

Figura 3 - Espectro de $\mathrm{RMN}^{1} \mathrm{H}$ de ésteres etílicos sintetizados a partir do óleo de andiroba com catalisador $\mathrm{Nb}_{2} \mathrm{O}_{5} / \mathrm{H}_{2} \mathrm{SO}_{4}$.

Estes resultados são similares aos encontrados por Aranda et al.(2009), que investigaram o uso do óxido de nióbio como catalisador heterogêneo para a esterificação de ácidos graxos de óleo de palma, utilizando metanol e etanol como agentes acilantes. Os autores relataram que as reações foram conduzidas em reator pressurizado à temperatura de $130{ }^{\circ} \mathrm{C}$ e concentração de catalisador de $3,4 \%(\mathrm{~m} / \mathrm{m})$, obtendo-se valores de conversão de 80 e $20 \%$ em reações com metanol e etanol, respectivamente. A diferença de rendimentos encontrados pelos autores se baseia na maior energia exigida para as reações de esterificação com etanol sendo necessárias temperaturas superiores a $150{ }^{\circ} \mathrm{C}$ para promover conversões de óleo elevadas. 
De forma geral, a atividade catalítica diminui com o aumento da cadeia alquílica do álcool utilizado nas reações de transesterificação, provavelmente devido ao efeito estérico, sendo assim, o etanol apresenta menor reatividade que o metanol. Este efeito foi observado tanto na catálise alcalina como na catálise ácida, sendo possível diminuir o impedimento estérico mediante o uso de relações molares etanol:óleo elevadas (Brandão et al., 2009). Pietre et al. (2010) estudaram a transesterificação de óleo de soja e metanol na presença de catalisador óxido de nióbio sulfatado a $70^{\circ} \mathrm{C}$ obtendo concentrações de ésteres metílicos na ordem de $40 \%$ após 5 h de reação.

$\mathrm{Na}$ literatura consultada, os estudos são direcionados principalmente para obtenção de ésteres a partir de ácidos graxos livres (ácido oleico e ácido esteárico) em reações bifásicas, obtendo-se rendimentos superiores a $80 \%$ em ésteres metílicos. A elevada conversão em processos de esterificação estaria associada ao caráter bifásico do meio reacional, constituído por catalisador sólido suspenso em ácido graxo dissolvido em álcool, enquanto que a reação de transesterificação ocorre em misturas trifásicas catalisador, óleo e álcool (Pietre et al., 2010).

$\mathrm{Na}$ Tabela 3, observa-se ainda que a variação da viscosidade dinâmica $(\triangle \mu)$ do produto final foi de 37 a $52 \%$ em relação ao óleo sem transesterificar (Reações 1 a 7). Entretanto, não se obteve uma correlação estrita dos valores de viscosidade com os valores rendimentos obtidos nas diferentes reações. Para a utilização dos ésteres etílicos como biocombustíveis, estes devem possuir certas caraterísticas conforme indicadas na normativa da Agência Nacional do Petróleo, Gás Natural e Combustível (ANP) que estabelece valores de viscosidade de 3 a $6 \mathrm{~mm}^{2} / \mathrm{s}$ e massa específica medida a $20^{\circ} \mathrm{C}$ de 850 a $900 \mathrm{~kg} / \mathrm{m}^{3}$ (ANP, 2012). Neste trabalho, os valores de viscosidades cinemáticas se encontram acima dos valores permitidos pela normativa ( 3 a $6 \mathrm{~mm}^{2} / \mathrm{s}$ ), em função da presença de triglicerídeos não convertidos em ésteres etílicos. Na literatura científica não foram encontrados trabalhos relacionados com a conversão de óleo de andiroba em ésteres etílicos mediante catalisador óxido de nióbio sulfatado, restringindo a comparação dos resultados obtidos no presente trabalho com aqueles disponíveis na literatura.

\section{CONCLUSÕES}

O catalisador heterogêneo ácido a base de óxido de nióbio sulfatado demonstrou desempenho promissor na conversão de óleos de alta acidez em ésteres de etila. Entretanto, em função das conversões limitadas (conversão máxima de $67 \%$ em ésteres de etila) estudos complementares estão em fase desenvolvimento visando à otimização das condições de síntese, bem como a reutilização dos catalisadores em vários ciclos catalíticos.

\section{REFERÊNCIAS}

ANP - Agência Nacional do Petróleo, Gás Natural e Biocombustíveis. Resolução ANP N¹4/2012. Disponível:http://nxt.anp.gov.br/nxt/gateway.dll/leg/resolucoes_anp/2012/maio/ranp\%2014\%20 -\%202012.xml. Acesso em 8 de abril. 2014

ARANDA, D.A.G.; GONÇALVES, J.A., PERES, J.S., RAMOS, A.L.D., MELO, C. A.E; ANTUNES, O.A.C; FURTADO, N. C; TAFLE, C. A. The use of acids, niobium oxide, and zeolites catalysts for esterification reactions. J. Phys. Org. Chem , v. 22, p. 709-716, 2009. 
BRANDÃO, R.F.; QUIRINO, R.L.; MELLO, V.M.; TAVARES, A.P.; PERES, A.C.; GUINHOS, F.; RUBIM, J.C.; SUAREZ, P.A. Synthesis, characterization and use of $\mathrm{Nb}_{2} \mathrm{O}_{5}$ based catalysts in producing biofuels by transesterification, esterification and pyrolysis. J. Braz. Chem. Soc, v. 20, p. 954-966, 2009.

CARVALHO, A.K.F. Síntese de biodiesel por transesterificação pela rota etílica: Comparação do desempenho de catalisadores heterogêneos. 2011. 105 p. Dissertação (Mestrado em Ciências Programa de Pós-Graduação em Engenharia Química na área de Processos Catalíticos e Biocatalíticos) - Escola de Engenharia de Lorena - Universidade de São Paulo, 2011.

KISS, A. A.; DIMIAN, A. C.; ROTHENBERG, G. Solid acids catalysts for biodiesel productiontowards sustainable energy. Adv. Synth. Cat., v. 348, p. 75-81. 2006.

KNOTHE, G.; GERPEN, J. V.; KRAHL, J.; RAMOS, L. P. Manual do Biodiesel, $1^{\text {a }}$ ed. São Paulo: Edgard Blucher, 2006.

MELO, R. S.; NETO, I.S.S., PINHEIRO, R.S., MOURA, K.R.M. SILVA, F.C., MACIEL, A.P. Obtenção de catalisadores heterogêneos de Nióbio modificado para a conversão de sebo bovino em biodiesel. Cadernos de Pesquisa, São Luís, v. 19, n. especial, jul. 2012.

NOWAK, I.; ZIOLEK, M. Niobium compounds: Preparation, characterization, and application in heterogeneous catalysis. Chem. Rev., v. 99, p. 3603-3624, 1999.

PIETRE, M.K.; ALMEIDA, L.C.P.; LANDERS, R.; VINHAS, R.C.G.; LUNA, F.J. $\mathrm{H}_{3} \mathrm{PO}_{4^{-}}$and $\mathrm{H}_{2} \mathrm{SO}_{4}$-treated niobic acid as heterogeneous catalyst for methyl ester production. Reac Kinet Mech. Cat., v. 99, p. 269-280, 2010.

SUAREZ, P.A.Z; MENEGHETTI, S.M.P. 70 aniversário do biodiesel em 2007: evolução histórica e situação atual no Brasil, Quim. Nova, v. 30, n. 8, p. 2068-2071, 2007.

VACCARO, G.L.R.; POHLMANN, C.; LIMA, A.C.; SANTOS, M.S.; SOUZA, C.B.; AZEVEDO, D. Prospective scenarios for the biodiesel chain of a Brazilian state. Renew. Sust. Energ. Rev., v. 14, p. 1263-1272, 2010. 